\title{
Review
}

\section{Nitric oxide in brain: diffusion, targets and concentration dynamics in hippocampal subregions}

\author{
Ana Ledo, João Frade, Rui M. Barbosa, João Laranjinha \\ Faculty of Pharmacy and Center for Neurosciences and Cell Biology, University of Coimbra, \\ Coimbra, Portugal
}

\begin{abstract}
Nitric oxide (NO) is a diffusible regulatory molecule involved in a wide range of physiological and pathological events. At the tissue level, a local and temporary increase in NOconcentration is translated into a cellular signal. From our current knowledge of biological synthesis and decay, the kinetics and mechanisms that determine NO concentration dynamics in tissues are poorly understood. Generally, NO mediates its effects by stimulating (e.g., guanylate cyclase) or inhibiting (e.g., cytochrome oxidase) transition metal-containing proteins and by post-translational modification of proteins (e.g., formation of nitrosothiol adducts). The borderline between the physiological and pathological activities of NO- is a matter of controversy, but tissue redox environment, supramolecular organization and compartmentalisation of $\mathrm{NO}^{*}$ targets are important features in determining $\mathrm{NO}^{*}$ actions. In brain, $\mathrm{NO}^{*}$ synthesis in the dependency of glutamate NMDA receptor is a paradigmatic example; the NMDA-subtype glutamate receptor triggers intracellular signalling pathways that govern neuronal plasticity, development, senescence and disease, suggesting a role for $\mathrm{NO}^{-}$in these processes. Measurements of $\mathrm{NO}^{-}$in the different subregions of hippocampus, in a glutamate NMDA receptor-dependent fashion, by means of electrochemical selective microsensors illustrate the concentration dynamics of $\mathrm{NO}^{*}$ in the sub-regions of this brain area. The analysis of NO concentration-time profiles in the hippocampus requires consideration of at least two interrelated issues, also addressed in this review. NO diffusion in a biological medium and regulation of $\mathrm{NO}$ activity.
\end{abstract}

(C) 2004 Elsevier Ltd. All rights reserved.

Abbreviations: CAPON, Carboxy-terminal PDZ ligand of nNOS; DOPAC, dihydroxyphenylacetic acid; EPR, electron paramagnetic resonance; LTP, long-term potentiation; NMDA, $N$-methyl-D-aspartate; NOS, nitric oxide synthase; PDZ, PSD-95 discs large/ZO-1 homology domain; PSD-95, post-synaptic density protein 95

${ }^{*}$ Corresponding author. Tel.: +351-9366-03799; fax: +351-239-852569.

E-mail address: laranjin@ci.uc.pt (J. Laranjinha). 
Keywords: Nitric oxide measurement; Nitric oxide dynamics; Nitric oxide signalling; Neurodegeneration; Hippocampus

\section{Contents}

1. Diffusion and regulation of nitric oxide activity in the brain . . . . . . . 76

2. Nitric oxide targets in physiologic and pathophysiologic pathways . . . . . . . 79

3. Measurement of NO in hippocampal subregions using electrochemical

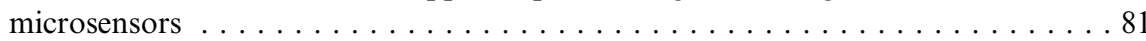

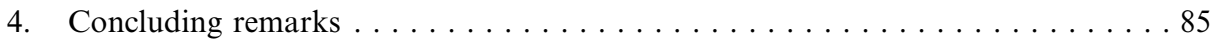

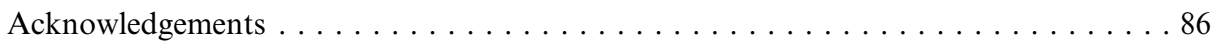

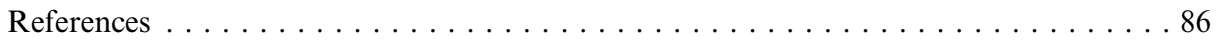

\section{Diffusion and regulation of nitric oxide activity in the brain}

Due to its low molecular weight and hydrophobic properties, NO easily permeates cell membranes (Shaw and Vosper, 1977) and may diffuse a few cell diameters from its site of synthesis to neighbouring cells, providing that the rate of transcellular diffusion is faster than the rate of its intracellular reactions (Lancaster, 1994; Wood and Garthwaite, 1994; Beckman and Koppenol, 1996; Lancaster, 1997). Studies designed to measure the distance of NO- diffusion under physiological conditions by means of electrochemical microsensors reported values of 100-200 $\mu \mathrm{m}$, rising within $10-15 \mathrm{~s}$ to a steady-state concentration, which are consistent with a high diffusion coefficient, $3300 \mu \mathrm{m}^{2} / \mathrm{s}$ (Malinski et al., 1993; Meulemans, 1994). A first strong experimental evidence for the intercellular diffusion of $\mathrm{NO}^{-}$in the brain came from the work of Schuman and Madison that were able to show NO-induced synaptic potentiation between paired neurons and synapses approximately $100 \mu \mathrm{m}$ distant in hippocampal slices (Schuman and Madison, 1994). In addition, modelling for NO· diffusion in brain predicted that the physiological sphere of influence of a single source producing $\mathrm{NO}$ for $1-10 \mathrm{~s}$ has a diameter of $200 \mu \mathrm{m}$, which corresponds to a volume of brain containing 2 million synapses (Wood and Garthwaite, 1994). These selected observations support the notion of NO as a diffusible intercellular messenger in the brain. This is clear in the case of long term potentiation (LTP, a leading experimental model for the synaptic changes that underlie learning and memory) in hippocampus. The formulation of LTP concept is in connection with NO as an intercellular messenger because it postulates the existence of a retrograde messenger; a species that once produced in the post-synaptic terminal was able to reach the pre-synaptic neuron and cause such an effect. In 1991, two independent groups 
showed that NO* was produced at the post-synaptic side of the synapses located at hippocampal CA1 subregion and that NO synthesis was required for LTP to be observed (O’Dell et al., 1991; Schuman and Madison, 1991). More recently, Arancio et al. were able to show that NO in cultured hippocampal neurons was produced in the post-synaptic side of the hippocampal synapse, diffused into the extracellular space and reached the pre-synaptic terminal, producing LTP (Arancio et al., 1996).

In spite of the NO random spread in all directions driven by a spatial concentration gradient from its original point of synthesis, because NO cannot be neither stored nor reuptaked into vesicles, the type and number of targets in the vicinity will determine and shape the NO concentration-time profile. Although NO is not particularly reactive with the majority of biomolecules, its very fast reactions with superoxide anion, lipid peroxyl radicals, transition metal-containing proteins, thiols (in protein residues and low molecular weight compounds, including glutathione and cysteine) and $\mathrm{O}_{2}$, probably dictate its half-life and regulate its bioavailability. For instance, in a model system consisting of activated macrophages, NO- fluxes were detected by means of a microelectrode at distances up to $500 \mu \mathrm{m}$ but the subsequent addition of proteins and lipids to the medium reduced its diffusional field (Porterfield et al., 2001). In aqueous solution, $\mathrm{NO}$ - undergoes a reaction with $\mathrm{O}_{2}$, finally producing nitrite, that proceeds slowly at the low $\mathrm{O}_{2}$ concentrations in tissues, but if considering the hydrophobicity of both $\mathrm{NO}^{-}$and $\mathrm{O}_{2}$, it is likely that the reaction of $\mathrm{NO} \cdot$ by $\mathrm{O}_{2}$ acquires relevance within the hydrophobic interior of biomembranes (Liu et al., 1998). Noteworthy, hemoglobin in red blood cells has been suggested to act as a global "sink", lowering severely the concentration of NO- (Lancaster, 1997). However, selective "sinks" have recently been proposed, including a flavoprotein active in some cell lines (Gardner et al., 2001) and an unknown protein present in brain homogenates and independent of several hemeproteins including hemoglobin and cytochrome oxidase (Griffiths and Garthwaite, 2001). According to this proposal, NO is consumed in the brain by an unknown protein that shapes NO signals. However, the existence of a specific biological mechanism for inactivating NO$\cdot$ has not been unequivocally identified.

In summary, the diffusional spread of NO in a biological setting will depend not only on its diffusibility but also on the amount and rate at which it is generated, the duration of release from a source cell and the rate (and compartmentalisation) of the $\mathrm{NO}$ reactions with $\mathrm{O}_{2}$ and other biological molecules.

From these notions an important question emerged related with NO signalling. What is the specificity of action of a highly diffusible, reactive and potentially toxic molecule in a signalling pathway? The answer to this question remains rudimentary. A first important observation is that the biosynthesis of $\mathrm{NO} \cdot$ is highly regulated. In neurons, NO synthesis occurs in a complex sequence of events involving the stimulation of NMDA-subtype glutamate receptors (a voltage-gated ion channel receptor activated by glutamate) and the influx of $\mathrm{Ca}^{2+}$ to the cytosol that upon binding to calmodulin activates neuronal nitric oxide synthase (nNOS); the whole process is achieved in time-scales of a few seconds (Garthwaite and Boulton, 1995). It is therefore assumed that a critical switch to control nNOS activity, provided that several cofactors including calmodulin, NADPH, FMN, FAD, tetrahydrobiopterin 
and heme are available, is a specific stimulus allowing $\mathrm{Ca}^{2+}$ influx (Bredt et al., 1992). The nNOS activity can be post-translationally regulated by phosphorylation catalysed by multiple kinases, including protein kinase C, cAMP-dependent protein kinase and $\mathrm{Ca}^{2+} /$ calmodulin-dependent protein kinase (Bredt et al., 1992), suggesting that NO synthesis in response to neuronal stimulation is modulated by multiple signalling cascades. Additional mechanisms of nNOS regulation include alternate mRNA splicing (reviewed in Alderton et al., 2001). Finally, a further level of complexity is added by the observation that NOS forms a $\mathrm{Fe}^{2+}$-heme intermediate, and, therefore, has the potential to experience a feedback inhibition by NO* via formation of a stable ferrous nitrosyl ( $\mathrm{Fe}^{2+}-\mathrm{NO} \cdot$ ) complex (reviewed in Alderton et al., 2001).

A second level of regulation is provided by the intracellular localization of nNOS and the spatial confinement of the components of the molecular machinery involved in the mechanisms of stimulation, synthesis and action (Fig. 1). The bivalent PDZ domain of nNOS targets the enzyme to membranes in synapses and interacts with a PDZ domain in neuron-specific PSD-95. Since PSD-95 also binds to glutamate

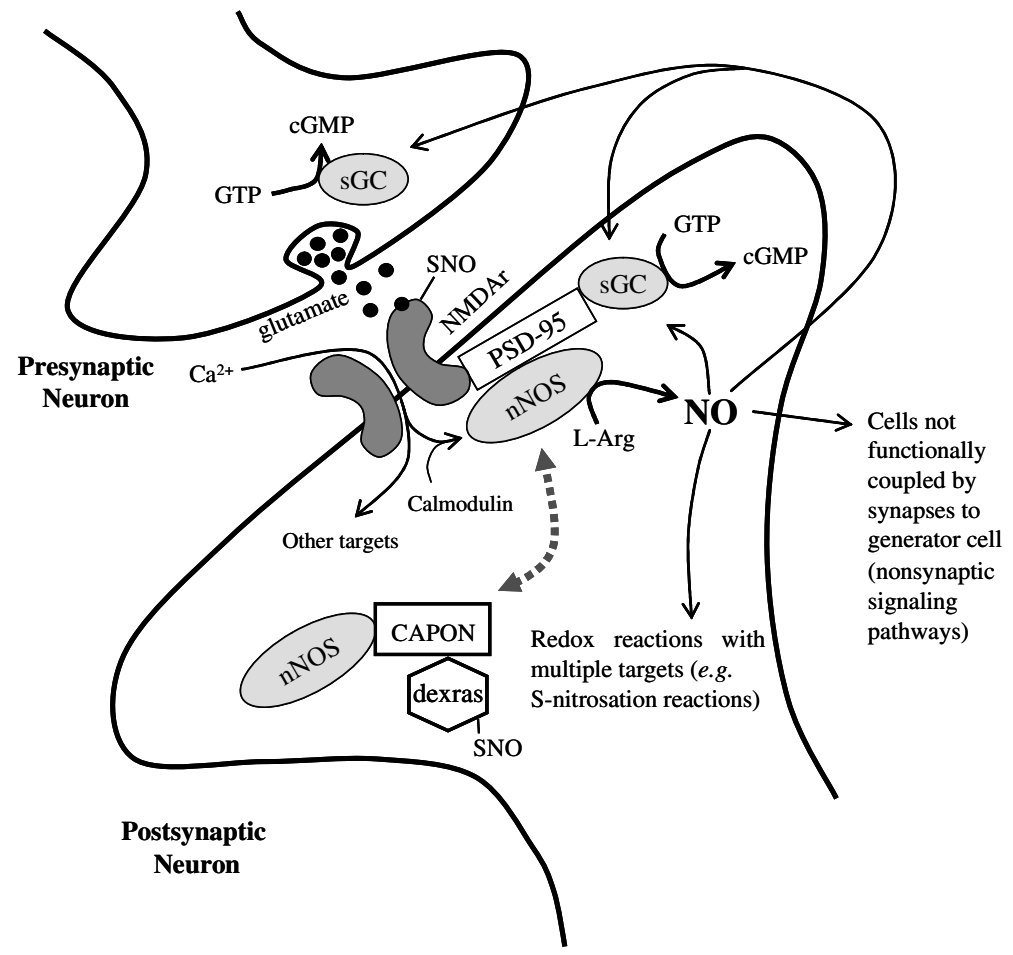

Fig. 1. Functional coupling of glutamate NMDA receptor with nitric oxide synthase and nitric oxide signalling pathways. The interaction of NMDA receptor with NOS via PSD-95 facilitates NO synthesis following $\mathrm{Ca}^{2+}$ influx. Adaptor protein CAPON regulates the supramolecular complex of NO- synthesis, linking nNOS to specific targets (e.g., small G proteins such as Dexras). Intra- and intercellular signalling pathways are mediated by interaction with soluble guanylate cyclase and thiol groups in proteins. The NMDA receptor is down-regulated by S-nitrosation of a critical cysteine residue. 
NMDA receptor through PZD domains, a picture emerges in which PSD-95 functionally couples NMDA receptor activation to nNOS activity (Christopherson et al., 1999). In addition to functional evidence coupling NMDA activity with NO- synthesis, co-localization of nNOS with NMDA receptors and PSD-95 in hippocampal dendritic spines using microscopic immunocytochemical methods optimized to detect synaptic antigens, adds strong support to the supramolecular organization of the signalling pathway across a synapse as a theme for the regulation of NO activity in the brain (Burette et al., 2002). A first consequence of such organization is that nNOS must be located within the localized sphere of increased $\mathrm{Ca}^{2+}$ concentration that occurs following activation of NMDA glutamate receptor, thus facilitating robust and rapid activation of the enzyme. Moreover, the physical coupling of NMDA receptor and nNOS by PSD95 can be regulated by the brain-specific adaptor protein CAPON that competes for the PDZ domain and detaches nNOS from the NMDA receptor (Jaffrey et al., 1998). Other proteins associated with CAPON (e.g., Dexras 1, synapsin) provide structural integrity to the multiprotein complex and might also be targets for NO· (Jaffrey et al., 2002). In this way, adapter proteins such as CAPON may deliver NO' to selective targets.

These are the general lines of thought for discussing the NO- signalling and the extracellular NO* measurement in hippocampus that are addressed in the following sections.

\section{Nitric oxide targets in physiologic and pathophysiologic pathways}

All isoforms of NOS can be expressed in the brain; eNOS in endothelial cells and neurons, nNOS in neurons (presumably in only $1-2 \%$ of the total neuronal population in many brain regions) and iNOS in activated microglia and astrocytes (Dawson and Dawson, 1998; Alderton et al., 2001). A neural role of NO was firstly suggested by observations relating the activation of glutamate NMDA receptor and NO synthesis in brain slices (reviewed in Garthwaite and Boulton, 1995). The glutamate NMDA receptor triggers intracellular signalling pathways that govern neuronal plasticity, development, senescence, and disease, suggesting a role for $\mathrm{NO}^{*}$ in these processes (Dawson and Dawson, 1998).

In signalling, the best characterized target for $\mathrm{NO}$ - is soluble guanylate cyclase (sGC) which is activated by NO producing cGMP (Ignarro, 1991); sGC is highly sensitive to NO' as half-maximal activation upon NO binding to the heme group occurs at 2-20 nM (Bellamy et al., 2000). However, recent findings point to the involvement of NO in signalling pathways independent of cGMP production (Boehning and Snyder, 2003) (Fig. 1). Noteworthy, those pathways mediated by NOredox chemistry with thiol groups in proteins and glutathione, likely involving transition-metal catalysis and interconversion among different redox forms of NO(e.g. $\mathrm{NO}^{+}$, the one-electron oxidation derivative). The formation of S-nitrosothiol proteins, occurring at a single critical cysteine residue has been described in many proteins and may regulate the function of transcription factors (pointing to a 
NO-mediated gene expression), ion channels, G-proteins and several enzymes (including protein kinases, phosphatases and caspases), structural proteins, etc. (Stamler et al., 2001). The selectivity of S-nitrosation of peptides and proteins is suggested by the observation that only a single cysteine residue within an acid-base or hydrophobic structural motif is modified in vivo. Although the vast majority of "S-nitrosylated" proteins have been described in vitro under conditions of exogenously added NO' donors, recent proteomic approaches have identified a population of endogenously S-nitrosylated proteins, most notably the glutamate NMDA receptor (Jaffrey et al., 2001; Matsumoto et al., 2003). In a way reminiscent of the kinase/phosphatase pathways, the dynamic regulation of proteins by nitrosation requires denitrosation but mechanisms are still uncertain.

Conversely to NMDA-dependent physiologic pathways, excessive activation of glutamate NMDA receptor, the process termed "excitotoxicity", represents a general mechanism underlying neurological disorders, ranging from Alzheimer's disease, Parkinson's disease, multiple sclerosis to AIDS dementia (Coyle and Puttfarcken, 1993; Dawson and Dawson, 1998). Although conflicting results exist, it has been established that NO mediates the toxicity of glutamate in primary cortical cultures and in a variety of other model systems (Dawson et al., 1991; Dawson and Dawson, 1998).

The current paradigm for NO- neurotoxicity states that its concentration is critical in determining whether it acts as a signalling molecule or as a toxin; in the later case the effects are mediated by NO-derived reactive species, imposing a "nitrosative stress". However, a change in concentration does not necessarily imply a qualitative modification of targets. For instance, NO* produced at very high concentrations, in the $\mu \mathrm{M}$ range, by an inducible NOS in macrophages plays an important role in the host response to infection, but NO exerts antimicrobial action by modifying selective thiol and metal centers of critical proteins in pathogens (Stamler et al., 2001). Thus, at high NO concentrations $(\mu \mathrm{M})$ in the brain, sGC activation and functional S-nitrosothiol formation are likely to occur. However, because repair systems might be overcame, cells and tissues have an additional difficulty to cope with a high number of dysfunctional events triggered by NO and related species, such as oxidation, nitrosation, and nitration of proteins and DNA. A number of works suggest that many of the neurotoxic actions of $\mathrm{NO}^{-}$are mediated by derived nitrogen species, including $\mathrm{NO}_{2}$ radical (Ischiropoulos, 1998) and peroxynitrite $\left(\mathrm{ONOO}^{-}\right)$, the reaction product of the termination reaction of $\mathrm{NO}^{*}$ and $\mathrm{O}_{2}^{-} \cdot$ (Radi et al., 1991). For instance, $\mathrm{ONOO}^{-}$was implicated in the apoptosis of hippocampal neurons of Mongolian gerbils subjected to cerebral ischemia (Cuzzocrea et al., 2000). On the other hand, superoxide dismutase, which scavenges $\mathrm{O}_{2}^{-}$, thus preventing $\mathrm{ONOO}^{-}$ formation, attenuates glutamate, NMDA and NO neurotoxicity (Dawson and Dawson, 1998). Curiously, NOS-containing neurons are enriched in manganese superoxide dismutase and are particularly resistant to NMDA and NO toxicity (Dawson and Dawson, 1998).

Moreover, nitrosative chemistry can trigger secondary oxidative modifications, as exemplified by oxidation of a cysteine residue in glutathione reductase mediated by S-nitrosoglutathione (Becker et al., 1998). Also, singlet oxygen, a highly reactive 
form of molecular oxygen, has been suggested to be a product of the reaction of NOwith $\mathrm{H}_{2} \mathrm{O}_{2}$ (Noronha-Dutra et al., 1993).

At the subcellular level it is important to consider the effects of NO on mitochondria (Boveris and Cadenas, 2000; Cadenas et al., 2000) leading to organelle dysfunction and the involvement of damaged mitochondria in the neurodegenerative diseases. In rat cortical neurons, NO- production and glutamate NMDA receptor activation is closely linked to intramitochondrial $\mathrm{ONOO}^{-}$formation (Solenski et al., 2003). In neurodegenerative pathologies, NO- from the iNOS of activated astrocytes or microglia might contribute to $\mathrm{NO}^{-}$production and inhibit persistently mitochondrial respiration in neurons (reviewed in Brown and Bal-Price, 2003). In this regard, the NO-dependent mitochondrial dysfunction leading to an energy deficient state may constitute a pathway driving neurodegeneration (Bolanos et al., 1997).

Paradoxically, NO and oxygen free radicals are produced in brain cells during normal activity and interact in signal transduction pathways (Bindokas et al., 1996). For instance, neuronal calcium signalling in rat cortical brain slices depends critically on NO and involves cellular oxygen free radicals utilization (Yermolaieva et al., 2000) and neuron-glia signalling in CA1 region of hippocampus requires $\mathrm{O}_{2}^{-}$and NO (Atkins and Sweatt, 1999).

Therefore, a complex picture emerges where oxygen free radicals and NO signals overlap, cooperate or produce antagonistic effects. Changes in the flux rates and compartmentalisation of $\mathrm{NO}^{-}$and oxygen free radicals may distort signalling cascades triggering pathologic cellular mechanisms. A remarkable demonstration of this concept was provided a decade ago by Lipton et al. (1993). Using NMDA receptor as a model the authors pointed out that the redox versality of NO permits its conversion from a neuroprotective molecule to a neurotoxin; neurotoxicity is mediated by $\mathrm{ONOO}^{-}$but neuroprotection is achieved by down-regulation of NMDA receptor activity by S-nitrosation (addition of $\mathrm{NO}^{+}$) of the receptor redox modulatory site. Since then, other observations including the potentiation of NO- synthesis by ascorbate (Heller et al., 1999) and the down-regulation of NMDA receptor by nitroxyl anion $\left(\mathrm{NO}^{-} ; \mathrm{Kim}\right.$ et al., 1999), the one-electron reduced form of $\mathrm{NO}^{-}$, stress the notion that a change in the neuronal redox milieu, modulated in part by the balance between reactive species (such as superoxide anion and $\mathrm{H}_{2} \mathrm{O}_{2}$ ) and neuroprotective compounds (most notably, ascorbate and glutathione) may determine the biological activity of NO.

Catecholamines may also be active components in modulating the redox environment because NO oxidizes dopamine (Daveu et al., 1997, Rettori et al., 2002) and DOPAC, yielding $o$-semiquinone radical species and nitroxyl anion in a process catalysed by superoxide dismutase (Laranjinha and Cadenas, 2002). In view of the nitroxyl-dependent decrease of NMDA receptor-evoked responses (Kim et al., 1999) these chemical interactions may acquire biological significance.

\section{Measurement of NO' in hippocampal subregions using electrochemical microsensors}

Development of sensitive and selective analytical techniques for the measurement of NO- in biological systems has been a matter of great concern (reviewed in Cadenas 
and Packer, 2002 and Taha, 2003). The techniques so far implemented in biomedical research explore the physical and chemical properties that support NO- biological activity and provide complementary information. One may tentatively group the design of methodologies in the following categories:

(1) Ex situ and indirect methods: examples include formation of stable adducts (e.g., EPR, and UV/VIS detection of hemoglobin- $-\mathrm{Fe}^{2+}-\mathrm{NO}$ and other NO-iron complexes), analysis of reaction products (e.g., hemoglobin-Fe $\mathrm{Fe}^{3+}, \mathrm{L}$-citrulline, nitrites and nitrates), chemiluminescence (gas phase reaction with ozone and reaction with luminol/hydrogen peroxide in the liquid phase) and reporter cell assays (Barker et al., 1999). These approaches require sample processing and, therefore, temporal resolution is lost.

(2) Incorporation of $\mathrm{NO}^{-}$-sensitive indicators in cells: fluorescent compounds have been developed that in connection with microscopy support imaging approaches to determine the spatial distribution of $\mathrm{NO}$ at cellular and sub-cellular levels. This interesting approach requires caution due to the influence of medium composition in the reaction of fluorophores and NO with in the fluorescence properties of fluorophores (Kojima et al., 2001). Compartmentalisation of the fluorophore, $\mathrm{pH}$, inner filter effects and photodecomposition are issues to be controlled.

(3) Analysis at the tip of a probe inserted into the environment of NO production: this seems a promising approach as the development of probes with small dimensions affords minimal disturbance of the physiological environment upon its insertion into tissues. Two technologies have been applied in the design of probes: electrochemistry and chemiluminescence, the later exhibiting much higher limits of detection.

Whereas each methodology has advantages for particular applications, most of these approaches provide data that is difficult to translate into the environment of NO* diffusional field in tissues (e.g., microdialysis, EPR) or rely on measurements of secondary products (e.g., nitrites and nitrates). Considering the role of NO as a diffusible messenger in the brain, the need to achieve a dynamic detection of NO at low $\mathrm{nM}$ levels in tissues with appropriate spatial and temporal resolution led to the development of selective electrochemical microsensors in connection with diverse electrochemical techniques (reviewed in Bedioui and Villeneuve, 2003). Commonly, electrochemical sensors exhibit a detection limit in the vicinity of $1-10 \mathrm{nM}$, a linear response up to $\mu \mathrm{M}$ range and an accuracy of $5-10 \%$.

The electrochemical measurement of NO with sensors in complex biological media implies modification of the electrode surface with organized coatings (without compromising response time) that improve sensitivity and selectivity. Shibuki firstly introduced a miniature electrochemical probe consisting in a Pt electrode covered with a gas-permeable membrane to successfully monitor endogenous NO* production (8-58 nM) in rat cerebellar slices (Shibuki, 1990). Later, Shibuki's probe enabled WPI (Sarasota, USA) to develop the first widely commercially available nitric oxide sensor, the ISO-NO. A second hallmark in the development of microsensors was the introduction of catalytic electrode surfaces by Malinski and Taha (1992), who used a carbon fiber electrode modified by the electropolymerization of Ni(II)-porphyrin. Following this advance, the deposition of polymeric films 
that catalyse NO- oxidation at the electrode surface became an attractive approach and several materials have been proposed, including different types of metalloporphyrins, metallophtalocyanines, copper-platinum microparticles, palladium and iridium oxide (Bedioui and Villeneuve, 2003). In most cases, the catalytic films are combined with molecular/ionic filters in order to achieve higher selectivity, including, as the most common, Nafion ${ }^{\circledR}, o$-phenylenediamine (Friedemann et al., 1996; Pontie et al., 1999), polylysine and polypyridinium (Mitchell and Michaelis, 1998).

Clearly, it is not only important to consider the design of the sensor to achieve optimal analytical performance in terms of sensitivity, selectivity and temporal resolution. Issues such as experimental conditions for multilayer coatings, construction procedures, electrical and temporal resolution of the complete detection system, calibration procedures, stability, electrochemical technique, etc, strongly influence analytical outcomes. Additionally, temperature and hydrodynamics cause changes in the amplitude of electrochemical signals that cannot be distinguished from variations in NO· concentration (Allen et al., 2002).

Amperometry is a highly sensitive analytical electrochemical technique (although suffering from lack of selectivity) often selected to detect NO in vivo, but, under conditions of high NO concentrations, selectivity can be improved by using fast cyclic voltammetry (FCV) (Ledo et al., 2002) and differential pulse voltammetry (Bedioui and Villeneuve, 2003). The oxidation and reduction peaks obtained with FCV provide the "redox signature" of the active species. In this way, catechols (dopamine, noradrenaline, DOPAC), indols (serotonine), nitrite and ascorbate can be clearly separated from NO signals (Ledo et al., 2002). For instance, Iravani et al., using a bare carbon electrode reported the simultaneous selective measurement of NO and dopamine in rat caudate putamen slices (Iravani et al., 1998).

Fig. 2 shows typical records of NO· profiles in the subregions of rat hippocampal slices, following stimulation of glutamate NMDA receptor with NMDA. The NOmicrosensors consisted in glass encased carbon fiber microelectrodes modified with $\mathrm{Nafion}^{\circledR}$ and $o$-phenylenediamine, or $\mathrm{Nafion}^{\circledR}$ and $\mathrm{Ni}(\mathrm{II})$-porphyrin. The reduced dimensions of the sensor (100-150 $\mu \mathrm{m}$ in length and $8 \mu \mathrm{m}$ in diameter) allowed high spatial resolution, while the amperometric approach conferred temporal resolution of recordings. The slices were challenged by an injection of NMDA at $50 \mu \mathrm{m}$ away from the microsensor insertion point. Recordings were performed in the pyramidal cell layer of subregions CA1 and CA3, the polymorphic cells of the hilus and the granular cell layer of the dentate gyrus, DG. The typical kinetic traces shown in Fig. 2 are sensitive to NOS inhibitors and were obtained independently of sensor type, in an indication that the signal is not an analytical artifact. Considering the high degree of structural integrity and functionality of the neuronal circuitry retained by the hippocampal slices, the signals shown represent an increase of NO- concentration from a low $\mathrm{nM}$ up to $\approx 200 \mathrm{nM}$, upon stimulation of NMDA receptor. In agreement with this assumption, Bon and Garthwaite showed that a tonic endogenous NO- low level is required for exogenously added $\mathrm{NO}^{-}$to facilitate long-term potentiation in hippocampal CA1 area (Bon and Garthwaite, 2003). Moreover, the ambient NO- 


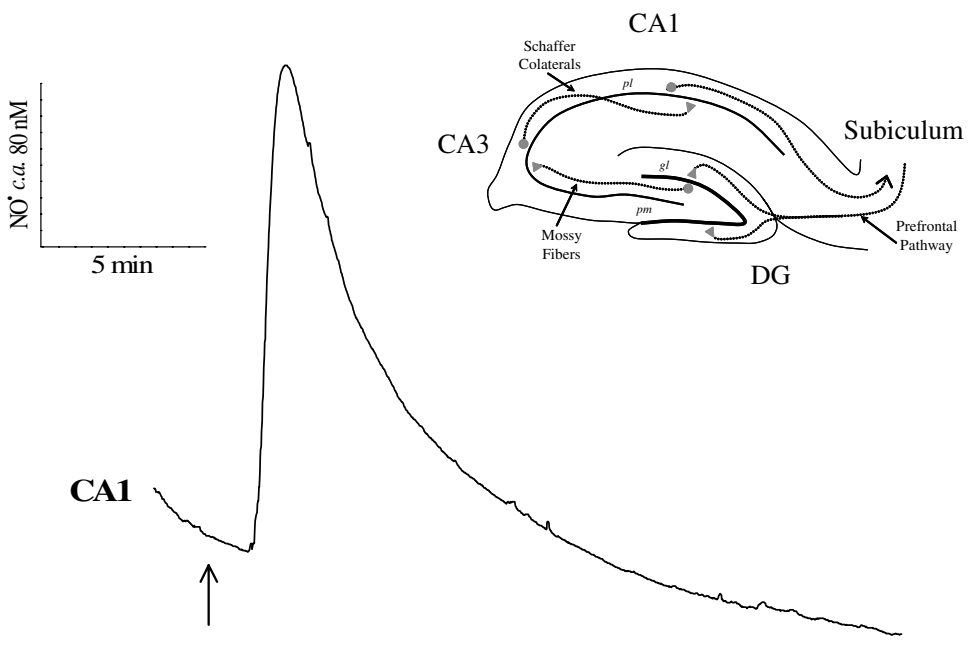

CA3

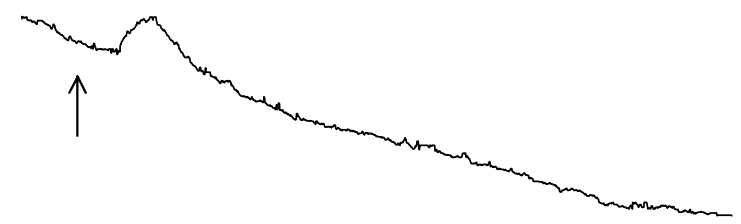

DG

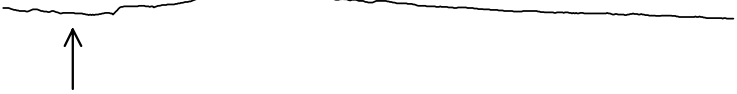

Hilus

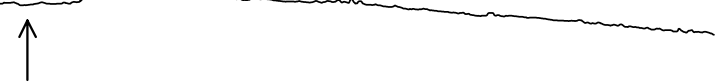

Fig. 2. Typical recording in subregions of hippocampal slices. The microsensor was inserted 100-200 $\mu \mathrm{m}$ into the tissue at $p l$ of $\mathrm{CA} 1$ and CA3, $p m$ of the hilus and $g l$ of the DG. Tissue stimulation (arrows) was accomplished by an injection of NMDA ( $5 \mathrm{mM}$ for $3 \mathrm{~s}) 50 \mu \mathrm{m}$ away from the microsensor insertion point, at the surface of the tissue. Inset: Schematic representation of the rat hippocampal slice, showing the divisions in subregions (CA1 and CA3 in the hippocampal proper and the dentate gyrus), the principal cell layers ( $p l$-pyramidal cell layer, $g l$-granular cell layer, $p m$-polymorphic cell layer or hilus) as well as the trisynaptic loop which represents the flow of information in this brain structure.

concentration in rat striatal slices was estimated as $2-10 \mathrm{nM}$ on basis of guanylate cyclase activity (Griffiths et al., 2002). 
Production of NO is more pronounced in hippocampus CA1 subregion. Considering only the response to a first stimulation, in CA3, DG and hilus signals are, respectively, $91 \%, 95 \%$ and $93 \%$ smaller as compared with those in CA1 area. The differences in NO concentration dynamics in the subregions of the hippocampus elicited through NMDA receptor are in agreement with the observation that NMDA-dependent LTP is observed mainly in the CA1 area of hippocampus (O'Dell et al., 1991; Schuman and Madison, 1991). The NO- levels in different subregions of hippocampus challenged with nicotine showed less dramatic differences; CA3 and DG peak amplitudes were $\approx 70 \%$ of peak amplitude in CA1 area (Smith et al., 1998). An imaging approach with diaminofluorescein derivatives also indicated that NO* is produced mainly in CA1 area in hippocampal slices under ischemic conditions (Kojima et al., 2001).

The dependency of NO- dynamics on the hippocampal subregions is not clear but is possibly related to different levels of expression of NOS. Immunohistochemical experiments (Burette et al., 2002; Wendland et al., 1994) and Western blots performed in total extracts of the different regions point in this direction (Liu et al., 2003). On the other hand, a gradient of expression has also been shown for NMDA receptors, with higher levels being detected in the CA1 subregion (Ozawa et al., 1998). However, these observations do not rule out other explanations, including a functional regulation of NO profiles by the redox environment. In addition to pressure injection, a stimulation by perfusion was also performed. Regardless of the type of stimulus the concentration dynamics of NO are qualitatively similar (unpublished results). The transient nature of NO* signals indicate that in spite of the fact that under the stimulation conditions applied multiple NO' sources are simultaneously being activated, steady-state concentrations are not achieved. As pointed out before (Lancaster, 1997), and in contrast with the NO mediated relaxation of the vasculature or under inflammatory conditions where NO concentration is most likely maintained constant (depending on the availability of substrates and cofactors), the activity of $\mathrm{NO}^{-}$as a messenger in the brain is exerted through transient and fluctuating concentrations.

\section{Concluding remarks}

The hippocampus is part of the medial temporal lobe and has been implicated in learning and memory formation. Impairment in this brain region is observed during normal ageing, and a more severe degeneration has been observed in neurodegenerative processes with severe memory impairment, as in Alzheimer's disease. The diffusional spread of $\mathrm{NO}^{\cdot}$ in hippocampus has not been quantified yet nor the relationship between NO concentration and cellular physiology. Certainly, further progress in understanding the role of NO' in the physiology and pathology of this brain region will be facilitated by the dynamic measurement of $\mathrm{NO}$ - concentrations under different stimulation conditions. The concentration-time profiles obtained with electrochemical microsensors is a first and promising approach to achieve such goal. 


\section{Acknowledgements}

\section{Supported by grants from Fundação Ciência e Tecnologia and FEDER (POCTI/ 2001/BCI/42365).}

\section{References}

Alderton, W.K., Cooper, C.E., Knowles, R.G., 2001. Nitric oxide synthases: structure, function and inhibition. Biochem. J. 357, 593-615.

Allen, B.W., Coury, L.A., Piantadosi, C.A., 2002. Electrochemical detection of physiologic nitric oxide: materials and methods. In: Cadenas, E., Packer, L. (Eds.), Meth. Enzymology, vol. 359, Academic Press Publ., pp. 125-134.

Arancio, O., Kiebler, M., Lee, C.J., Lev-Ram, V., Tsien, R.Y., Kandel, E.R., Hawkins, R.D., 1996. Nitric oxide acts directly in the presynaptic neuron to produce long-term potentiation in cultured hippocampal neurons. Cell 87, 1025-1035.

Atkins, C.M., Sweatt, J.D., 1999. Reactive oxygen species mediate activity-dependent neuron-glia signalling in output fibers of the hippocampus. J. Neurosc. 19, 241-248.

Barker, S.L., Zhao, Y., Marletta, M.A., Kopelman, R., 1999. Cellular applications of a sensitive and selective fiber-optic nitric oxide biosensor based on a dye-labeled heme domain of soluble guanylate cyclase. Anal. Chem. 71, 2071-2075.

Becker, K., Savvides, S.N., Keese, M., Schirmer, R.H., Karplus, P.A., 1998. Enzyme inactivation through sulfhydryl oxidation by physiologic NO-carriers. Nat. Struct. Biol. 5, 267-271.

Beckman, J.S., Koppenol, W.H., 1996. Nitric oxide, superoxide, and peroxynitrite: the good the bad and the ugly. Am. J. Physiol. 271, C1424-C1437.

Bedioui, F., Villeneuve, N., 2003. Electrochemical nitric oxide sensors for biological samples-principle, selected examples and applications. Electroanalysis 15, 5-18.

Bellamy, T.C., Wood, J., Goodwin, D.A., Garthwaite, J., 2000. Rapid desensitization of the nitric oxide receptor, soluble guanylyl cyclase, underlies diversity of cellular cGMP responses. Proc. Natl. Acad. Sci. USA 97, 2928-2933.

Bindokas, V.P., Jordán, J., Lee, C.C., Miller, R.J., 1996. Superoxide production in rat hippocampal neurons: selective imaging with hydroethidine. J. Neurosc. 16, 1324-1336.

Boehning, D., Snyder, S.H., 2003. Novel neural modulators. Annu. Rev. Neurosci. 26, 105-131.

Bolanos, J., Almeida, A., Stewart, V., Peuchen, S., Land, J.M., Clark, J.B., Heales, S.J.R., 1997. Nitric oxide-mediated mitochondrial damage in the brain: mechanisms and implications for neurodegenerative diseases. J. Neurochem. 68, 2227-2240.

Bon, C.L., Garthwaite, J., 2003. On the role of nitric oxide in hippocampal long term potentiation. J. Neurosci. 23, 1941-1948.

Boveris, A., Cadenas, E., 2000. Mitochondrial production of hydrogen peroxide regulation by nitric oxide and the role of ubisemiquinone. IUBMB Life 50, 245-250.

Bredt, D.S., Ferris, C.D., Snyder, S.H., 1992. Nitric oxide synthase regulatory sites. Phosphorylation by cyclic AMP-dependent protein kinase, protein kinase $\mathrm{C}$ and calcium/calmodulin protein kinase: identification of flavin and calmodulin binding sites. J. Biol. Chem. 267, 976-981.

Brown, G.C., Bal-Price, A., 2003. Inflammatory neurodegeneration mediated by nitric oxide, glutamate, and mitochondria. Mol. Neurobiol. 27, 325-355.

Burette, A., Zabel, U., Weinberg, R.J., Schmidt, H.H.H., Valtschanoff, J.G., 2002. Synaptic localization of nitric oxide synthase and soluble guanylyl cyclase in the hippocampus. J. Neurosc. 22, 8961-8970.

Cadenas, E., Packer, L. (Eds.), 2002. Nitric oxide, Part D: nitric oxide detection, mitochondria and cell functions and peroxynitrite reactions. Meth. Enzymol., vol. 359, Academic Press Publ.

Cadenas, E., Poderoso, J.J., Antunes, F., Boveris, A., 2000. Analysis of the pathways of nitric oxide utilization in mitochondria. Free Rad. Res. 33, 747-756. 
Christopherson, K.S., Hillier, B.J., Lim, W.A., Bredt, D.S., 1999. PSD-95 assembles a ternary complex with the $N$-methyl-D-aspartic acid receptor and a bivalent neuronal NO' synthase PDZ domain. J.Biol. Chem. 274, 27467-27473.

Coyle, J., Puttfarcken, P., 1993. Oxidative stress, glutamate, and neurodegenerative disorders. Science 262, 689-895.

Cuzzocrea, S., Mazzon, E., Costantino, G., Serraino, I., Dugo, L., Calabro, G., Cucinotta, G., De Sarro, A., Caputi, A.P., 2000. Benefitial effects of n-acetylcysteine on ischemic brain injury. Br. J. Pharmacol. 130, 1219-1226.

Daveu, C., Servy, C., Dendane, M., Marin, P., Ducrocq, C., 1997. Oxidation and nitration of catecholamines by nitrogen oxides derived from nitric oxide. Nitric Oxide 1, 234-243.

Dawson, V.L., Dawson, T.M., 1998. Nitric oxide in neurodegeneration. Prog. Brain Res. 118, $215-229$.

Dawson, V.L., Dawson, T.M., London, E.D., Bredt, D.S., Snyder, S.H., 1991. Nitric oxide mediates glutamate neurotoxicity in primary cortical cultures. Proc. Natl. Acad. Sci. USA 88, 6368-6371.

Friedemann, M.N., Robinson, S.W., Gerhardt, G.A., 1996. $o$-Phenylenediamine-modified carbon fiber electrodes for the detection of nitric oxide. Anal. Chem. 68, 2621-2628.

Gardner, P.R., Martin, L.A., Hall, D., Gardner, A.M., 2001. Dioxygen-dependent metabolism of nitric oxide in mammalian cells. Free Radical Biol. Med. 31, 191-204.

Garthwaite, J., Boulton, C.L., 1995. Nitric oxide signaling in the central nervous system. Annu. Rev. Physiol. 57, 683-706.

Griffiths, C., Garthwaite, J., 2001. The shaping of nitric oxide signals by a cellular sink. J. Physiol. 536, $855-862$.

Griffiths, C., Garthwaite, G., Goodwin, D.A., Garthwaite, J., 2002. Dynamics of nitric oxide during simulated ischaemia-reperfusion in rat striatal slices measured using an intrinsic biosensor, soluble guanyllyl cyclase. Eur. J. Neurosc. 15, 962-968.

Heller, R., Munscher-Paulig, F., Grabner, R., Till, U., 1999. L-Ascorbic acid potentiates nitric oxide synthesis in endothelial cells. J. Biol. Chem. 274, 8254-8260.

Ignarro, L.J., 1991. Signal transduction mechanisms involving nitric oxide. Biochem. Pharmacol. 41, 485490.

Iravani, M.M., Millar, J., Kruk, Z.L., 1998. Differential release of dopamine by nitric oxide in subregions of rat caudate putamen slices. J. Neurochem. 71, 1969-1977.

Ischiropoulos, H., 1998. Biological tyrosine nitration: a pathophysiological function of nitric oxide and reactive oxygen species. Arch. Biochem. Biophys. 356, 1-11.

Jaffrey, S.R., Snowman, A.M., Eliasson, M.J., Cohen, N.A., Snyder, S.H., 1998. CAPON: a protein associated with neuronal nitric oxide synthase that regulates its interactions with PSD95. Neuron 20, $115-124$.

Jaffrey, S.R., Erdjument-Bromage, H., Ferris, C.D., Tempst, P., Snyder, S.H., 2001. Protein Snitrosylation: a physiological signal for neuronal nitric oxide. Nature Cell Biol. 3, 193-197.

Jaffrey, S.R., Benfenati, F., Snowman, A.M., Czernik, A.J., Snyder, S.H., 2002. Neuronal nitric-oxide synthase localization mediated by a ternary complex with synapsin and CAPON. Proc. Natl. Acad. Sci. USA 99, 3199-3204.

Kim, W.K., Choi, Y.B., Rayudu, P.V., Das, P., Asaad, W., Arnelle, D.R., Stamler, J.S., Lipton, S.A., 1999. Attenuation of NMDA receptor activity and neurotoxicity by nitroxyl anion $\mathrm{NO}^{-}$. Neuron 24 , 461-469.

Kojima, H., Hirata, M., Kudo, Y., Kikuchi, K., Nagano, T., 2001. Visualization of oxygen-concentrationdependent production of nitric oxide in rat hippocampal slices during aglycemia. J. Neurochem. 76, 1404-1410.

Lancaster, J.R., 1994. Simulation of the diffusion and reaction of endogenously produced nitric oxide. Proc. Natl. Acad. Sci. USA 91, 8137-8141.

Lancaster, J.R., 1997. A tutorial on the diffusibility and reactivity of free nitric oxide. Nitric Oxide 1, 18-30.

Laranjinha, J., Cadenas, E., 2002. Oxidation of DOPAC by nitric oxide: effect of superoxide dismutase. J. Neurochem. 81, 892-900.

Ledo, A., Barbosa, R.M., Frade, J., Laranjinha, J., 2002. Nitric oxide monitoring in hippocampal brain slices using electrochemical methods. Meth. Enzymol. 359, 111-125. 
Lipton, S.A., Choi, Y.B., Pan, Z.H., Lei, S.Z., Chen, H.S., Sucher, N.J., Loscalzo, J., Singel, D.J., Stamler, J.S., 1993. A redox-based mechanism for the neuroprotective and neurodestructive effects of nitric oxide and related nitroso-compounds. Nature 364, 626-632.

Liu, X., Miller, M.J.S., Joshi, M.S., Thomas, D.D., Lancaster, J.R., 1998. Accelerated reaction of nitric oxide with oxygen within the hydrophobic interior of biological membranes. Proc. Natl. Acad. Sci. USA 95, 2175-2179.

Liu, P., Smith, P.F., Appleton, I., Darlington, C.L., Bilkey, D.K., 2003. Regional variations and agerelated changes in nitric oxide synthase and arginase in the sub-regions of the hippocampus. Neuroscience 119, 679-687.

Malinski, T., Taha, Z., 1992. Nitric oxide release from a single cell measured in situ by a porphyrinic-based microsensor. Nature 358, 676-678.

Malinski, T., Taha, Z., Grunfeld, S., Patton, S., Kapturczak, M., Tomboulian, P., 1993. Diffusion of nitric oxide in the aorta wall monitored in situ by porphyrinic microsensors. Biochem. Biophys. Res. Commun. 193, 1076-1082.

Matsumoto, A., Comatas, K.E., Liu, L., Stamler, J.S., 2003. Screening for nitric oxide-dependent proteinprotein interactions. Science 301, 657-661.

Meulemans, A., 1994. Diffusion coefficients and half-lives of nitric oxide and $N$-nitroso-L-arginine in rat cortex. Neurosci. Lett. 171, 89-93.

Mitchell, K.M., Michaelis, E.K., 1998. Multimembrane carbon fiber electrodes for physiological measurements of nitric oxide. Electroanalysis 10, 81-88.

Noronha-Dutra, A.A., Epperlein, M.M., Woolf, N., 1993. Reaction of nitric oxide with hydrogen peroxide to produce potentially cytotoxic singlet oxygen as a model for nitric oxide-mediated killing. FEBS Lett. 321, 59-62.

O'Dell, T.J., Hawkins, R.D., Kandel, E.R., Arancio, O., 1991. Tests of the roles of two diffusible substances in long-term potentiation: evidence for nitric oxide as a possible early retrograde messenger. Proc. Natl. Acad. Sci. USA 88, 11285-11289.

Ozawa, S., Kamiya, H., Tsuzuki, K., 1998. Glutamate receptors in the mammalian central nervous system. Prog. Neurobiol. 54, 581-618.

Pontie, M., Bedioui, F., Devynck, J., 1999. New composite modified carbon microfibers for sensitive and selective determination of physiologically relevant concentrations of nitric oxide in solution. Electroanalysis 11, 845-850.

Porterfield, D.M., Laskin, J.D., Jung, S.K., Malchow, R.P., Billack, B., Smith, P.J., Heck, D.E., 2001. Proteins and lipids define the diffusional field of nitric oxide. Am. J. Physiol. Lung Cell Mol. Physiol. 281, L904-L912.

Radi, R., Beckman, J.S., Bush, K.M., Freeman, B.A., 1991. Peroxynitrite-induced membrane lipid peroxidation: the cytotoxic potential of superoxide and nitric oxide. Arch. Biochem. Biophys. 288, 481-487.

Rettori, D., Tang, Y., Dias Jr., L.C., Cadenas, E., 2002. Pathways of dopamine oxidation mediated by nitric oxide. Free Radic. Biol. Med. 33, 685-690.

Schuman, E.M., Madison, D.V., 1991. A requirement for the intercellular messenger nitric oxide in longterm potentiation. Science 254, 1503-1506.

Schuman, E.M., Madison, D.V., 1994. Locally distributed synaptic potentiation in the hippocampus. Science 263, 532-536.

Shaw, A.W., Vosper, A.J., 1977. Solubility of nitric oxide in aqueous and nonaqueous solvents. J. Chem. Soc. Faraday Trans. 8, 1239-1244.

Shibuki, K., 1990. An electrochemical microprobe for detecting nitric oxide release in brain tissue. Neurosci. Res. 9, 69-76.

Smith, D.A., Hoffman, A.F., David, D.J., Adams, C.E., Gerhardt, G.A., 1998. Nicotine-evoked nitric oxide release in the rat hippocampal slice. Neurosc. Lett. 255, 127-130.

Solenski, N.J., Kostecki, V.K., Dovey, S., Periasamy, A., 2003. Nitric oxide-induced depolarization of neuronal mitochondria: implications for neuronal death. Mol. Cell. Neurosci. 24, 1151-1169.

Stamler, J.S., Lamas, S., Fang, F.C., 2001. Nitrosylation: the prototypic redox-based signaling mechanism. Cell 106, 675-683. 
Taha, Z.H., 2003. Nitric oxide measurements in biological samples. Talanta 61, 3-10.

Wendland, B., Schweizer, F.E., Ryan, T.A., Nakane, M., Murad, F., Scheller, R.H., Tsien, R.W., 1994. Existence of nitric oxide synthase in rat hippocampal pyramidal cells. Proc. Natl. Acad. Sci. USA 91, 2151-2155.

Wood, J., Garthwaite, J., 1994. Models of the diffusional spread of nitric oxide: implications for neural nitric oxide signalling and its pharmacological properties. Neuropharmacol. 33, 1235-1244.

Yermolaieva, O., Brot, N., Weissbach, H., Heinemann, S.H., Hoshi, T., 2000. Reactive oxygen species and nitric oxide mediate plasticity of neuronal calcium signaling. Proc. Natl. Acad. Sci. USA 97, 448-453. 